\title{
Partitioning variation in nutrient composition data of common feeds and mixed diets on commercial dairy farms
}

\author{
N. R. St-Pierre ${ }^{1}$ and W. P. Weiss \\ Department of Animal Sciences, Ohio Agricultural Research and Development Center, The Ohio State University, Wooster 44691
}

\begin{abstract}
A large project involving commercial dairy farms was undertaken to identify important sources of variation in composition data of common feeds and mixed diets. This information is needed to develop appropriate sampling schedules for feeds and should reduce the uncertainty associated with the nutrient composition of delivered diets. The first subproject quantified sources of variation in the composition of corn and haycrop silages over a 2 -wk period. Silages from 11 commercial dairy farms in Ohio and Vermont were sampled daily over a 14-d period. Most silages were sampled in duplicate each day, and all samples were assayed in duplicate. Total variance was partitioned into analytical, sampling, farm, and true day-to-day components. Farm was the largest source of variation, but within-farm variance was our primary interest. Sampling variance comprised 30 to $81 \%$ of within-farm variance depending on nutrient and type of silage. For dry matter, true day-to-day variation was the greatest source of variance, but for most other nutrients, sampling was the largest source of within-farm variation. The second subproject consisted of sampling feeds and total mixed rations (TMR) from 47 commercial dairy farms across the United States. Feeds and TMR were sampled monthly. Because samples were not assayed in duplicate, source of variation included farm, month, and residual (sampling plus analytical). For corn and alfalfa silages, month-to-month variation over a 12-mo period comprised about twice as much of the total within-farm variation as did day-today variation over a 14-d period in the first subproject. Although month-to-month variation was greater than sampling variation, sampling still accounted for 9 to $37 \%$ of the total within-farm variance for those 2 feeds. For TMR, sampling plus analytical variance accounted for approximately 40 to $70 \%$ of the total within-farm variance (depending on the nutrient). Variance components were estimated for several nutrients and for several common feeds. The contributions to total vari-
\end{abstract}

Received February 5, 2015.

Accepted March 31, 2015.

${ }^{1}$ Corresponding author: st-pierre.8@osu.edu ance differed depending on feed and nutrient, but the information provided will help in determining whether on-farm samples should be taken and if so, how often. A major implication of this project is that sampling is a substantial source of variation in silages, concentrates, and TMR, and data from a single sample are likely not highly reliable.

Key words: feed sampling, feed composition, variation

\section{INTRODUCTION}

Variation in nutrient composition of feeds leads to uncertainty in nutrient supply, which can affect diet formulation strategies. To reduce the risk of nutrient deficiencies when, by chance, ingredients contain less than anticipated nutrient concentrations, diets are often formulated to contain excess nutrients (i.e., include safety factors; Sniffen et al., 1993). Safety factors reduce the risk of nutrient deficiencies, but they can inflate feed costs and result in increased excretion of environmentally important nutrients such as $\mathrm{P}$ and $\mathrm{N}$ via manure. The degree of variation in nutrient composition should be considered when developing safety factors; highly variable diets should have greater safety factors than more consistent diets (Black and Hlubik, 1980).

Estimates of variability (i.e., SD) in nutrient composition of feeds are available from several sources (Kertz, 1998; NRC, 2001; St-Pierre and Cobanov, 2007b; DairyOne, 2015; NANP, 2015). However, these standard deviation (SD) estimates are for broad populations (e.g., corn silage grown in the United States in the last $3 \mathrm{yr})$ and contain numerous sources of variation including sampling, analytical, hybrid, growing conditions, maturity, manufacturing practices, and so on. For many feeds including home-grown forages, the within-farm variation in composition should be used to evaluate the nutritional risk associated with a given diet rather than the variation within a broad population. The within-farm variance includes fewer sources of variation and, therefore, must be less than the nutritional variation in broad populations. In addition to having estimates of variances for appropriate 
populations, separating the total variance into variance components that are associated with measurements (i.e., analytical and sampling) from true compositional variance is needed to develop efficient feed-sampling schedules (St-Pierre and Cobanov, 2007a,b) and allow the application of stochastic programming in ration formulation (St-Pierre and Harvey, 1986). For this paper, true variation is defined as the intrinsic variation in a feed absent from the variation caused by the observer (laboratory, sampling, assay, and so on). True variation results from differences in plant genetics, environment, soil, manufacturing differences, and so on. Only true variation should affect animal productivity and, thus, the economic value of a feed. Only the true variation should be included when using stochastic programming in diet formulation.

Separating total variance into components associated with measurement from true compositional variance is also important when using composition data to monitor or control the nutrition program on a farm. Sampling and analyzing the TMR can be used to evaluate whether the diet that is delivered to a pen matches the nutrient specifications of the formulated diet (Sova et al., 2014). By sampling TMR over different days, consistency of the TMR can also be evaluated. However, consistency and accuracy should be evaluated when results only include true compositional variance, not the variance associated with measurement.

To our knowledge, no published estimates are available on the within-farm true variance in the composition of feeds as opposed to broader population variances, but true within-farm variance estimates are needed, as explained previously (St-Pierre and Harvey, 1986). Data are also needed to partition the contribution of sampling and analytical variance in the total variance in the nutritional composition of feedstuffs and TMR. The objectives of this study were to (1) estimate variances in nutrient composition of common feeds on commercial dairy farms in the United States; (2) partition sampling and analytical variances from true withinfarm variance in the composition of common feeds; and (3) estimate variance in nutrient composition of TMR on commercial dairy farms and partition that variance into measurement components (sampling and analytical) and true within-farm variance.

\section{MATERIALS AND METHODS}

\section{Daily Sampling Project}

Eight dairy farms in the vicinity of Wooster, Ohio, and 3 dairy farms in the vicinity of Ferrisburgh, Vermont, agreed to participate in this project (this was not a random sample of farms). Farm size ranged from
120 to 1,400 lactating cows. Corn silage (11 farms) and haycrop silage (9 farms but 11 independent silos of haycrop silage) were sampled each day for 14 consecutive days over a period when silage was not expected to change greatly (e.g., change in crop year). Across farms, samples were taken at different times during the year. Corn silage was stored in upright silos (1 farm), bags ( 2 farms), and bunkers ( 8 farms). Haycrop silage was stored in upright silos (1 farm), bags (2 farms), and bunker silos ( 6 farms but 9 silages). No information was available as to whether samples represented different fields. Depending on the farm, the haycrop silage included alfalfa, cool-season grasses, mixtures of alfalfa and grass, and annual rye. The 8 Ohio farms were visited, and the feeder was instructed in sampling technique (a single person took all the samples within a given farm). All samples from the Vermont farms were taken by a single person.

Briefly, the technique for sampling from a bunker silo was to first remove a large quantity of silage from the face of silo (at most farms this was via a silage defacer). A portion of the removed silage was scooped into a loader bucket and then 3 or 4 handfuls of silage from the bucket were taken and placed into a $20-\mathrm{L}$ pail. That process was repeated with 2 or 3 loader buckets of silage. The contents of the pail was mixed by hand and then dumped out on a clean surface and the pile divided into quarters, with one-quarter placed into a plastic bag and refrigerated. For silage stored in bags, approximately 5 handfuls of silage were taken from across the face at the beginning of the feeding session and then this was repeated after some silage was removed to feed cows. The silage was placed into 20-L pails and subsampled as above. For upright silos, a 20-L bucket was used to collect a sample as the silage was unloaded. A sample was taken 2 or 3 times during the course of silage unloading, and the contents of the buckets were mixed together and subsampled as described above. The 3 farms in Vermont and 4 of the Ohio farms took duplicate samples of the corn and haycrop silages each day, using the process described above. The duplicate samples came from independent $20-\mathrm{L}$ pails; they did not come from subsamples from the same container. The other 4 farms in Ohio provided only single daily samples from each type of silage. After sampling, samples from Ohio farms were stored in a refrigerator for up to $3 \mathrm{~d}$ and then transported to the Ohio Agricultural Research and Development Center and frozen at $-20^{\circ} \mathrm{C}$ until they were assayed. The samples from the Vermont farms were frozen daily and then shipped to the Ohio Agricultural Research and Development Center.

Samples were thawed, and 2 subsamples were removed from each bag ( 100 g each), weighed, and dried 
at $100^{\circ} \mathrm{C}$ for $48 \mathrm{~h}$ to measure DM concentration. A third subsample $(\sim 200 \mathrm{~g})$ was dried at $60^{\circ} \mathrm{C}$ for $48 \mathrm{~h}$ and then ground through a 1-mm screen (Wiley Mill, Arthur A. Thomas, Philadelphia, PA). Ground samples were analyzed in duplicate for NDF (Ankom ${ }^{200}$ Fiber Analyzer, Ankom Technology, Fairport, NY) with sodium sulfite and amylase (Sigma A3306, Sigma Diagnostics, St. Louis, MO), ash (method 942.05; AOAC International, 2000), and CP (method 984.13.4.2.09; AOAC International, 2000). Corn silage was assayed for starch (Weiss and Wyatt, 2000). No data were discarded even if differences between duplicates were large.

\section{Monthly Sampling Project}

Fourteen nutritionists from across the United States (excluding $\mathrm{OH}$ ) were contacted and agreed to participate in this project. They were each asked to identify up to 4 client farms. Twenty-eight farms representing diverse geographic regions (farms were located in CA, IA, MI, NM, NY, SD, TX, UT, and WI) agreed to participate (one farm withdrew from the project after $2 \mathrm{mo}$ ). Twenty-one dairy farms (15 different nutritionists) from across Ohio were contacted and agreed to participate in a more intensive data-collection project (only information on feed and TMR composition will be discussed in this paper). One Ohio farm withdrew from the project after 3 mo. Therefore, the total number of farms used for data analyses in this project was 47. Nutritionists were requested to sample all major ingredients that were put into the high-group TMR (the definition of "high group" was at the discretion of the farm) at approximately monthly intervals for 12 consecutive months. Only primary ingredients were sampled; mixtures of feed ingredients were not. Ingredients that were predominantly minerals or supplemental fat were not sampled. The nutritionists could modify the ration as they deemed necessary. The TMR for the high group was sampled monthly on the same day that ingredients were sampled. The TMR was sampled immediately after it was delivered to the pen by visually dividing the feed bunk into approximate thirds and then taking 5 handfuls of TMR from the center of each one-third section (15 handfuls representing the entire depth of the TMR pile). The handfuls of TMR were put into a 20-L bucket, and the contents were mixed by hand and dumped onto a clean surface. The sample was divided into quarters, and one-quarter was collected and placed in a sample bag. Duplicate samples of TMR (the entire process was repeated to obtain the duplicate) were taken every month. All nutritionists were sent the same sampling protocol as described above. The same basic procedure was used for concentrates. Hay or straw, if fed, was sampled using a core sampler. Samples were sent to a single laboratory (Cumberland Valley Analytical Services Inc., Hagerstown, MD) on the day of collection if possible. If that could not be done, wet samples (e.g., silage) were stored in a refrigerator until they were sent to the laboratory. The DM concentrations of wet feeds were determined by drying samples at $65^{\circ} \mathrm{C}$ overnight followed by drying at $105^{\circ} \mathrm{C}$ for $3 \mathrm{~h}$. For dry feeds, DM was measured by drying at $135^{\circ} \mathrm{C}$ for $3 \mathrm{~h}$ (method 930.15; AOAC International, 2000). Samples (as received for dry samples and wet samples following $65^{\circ} \mathrm{C}$ drying) were ground and assayed for NDF (Van Soest et al., 1991), CP (method 990.03, AOAC International, 2000), ash (method 942.05, AOAC International, 2000), and minerals (method 985.01, AOAC International, 2000). Assays were not conducted in duplicate.

\section{Statistical Analysis}

The main objective of the daily sampling experiment was to partition within-farm variance of nutrient composition of corn and haycrop silages into 3 separate variance components: sampling variance, analytical variance, and true day-to-day variance. Because multiple farms were used, farm-to-farm variance was also estimated, but this was not a primary objective. For each nutrient within each feed, random effects models were fitted to the daily and monthly data using the MIXED procedure of SAS V9.3 (SAS Institute, 2011). For the daily data, the model included the random effects of farm, sample day within farm, duplicate sample within farm and sample day, and a residual error term, according to the following statistical model:

$$
Y_{i j k l}^{n: z}=\mu+f_{i}+d_{j: i}+s_{k: i j}+e_{i j k l},
$$

where $Y_{i j k l}^{n: z}$ is the observed value for nutrient $n$ within feed $z ; \mu$ is the overall population mean; $f_{i}$ is the random effect of farm $i, \sim \mathrm{N}\left(0, \sigma_{f}^{2}\right) ; d_{j: i}$ is the random effect of day $j$ within farm $i, \sim \mathrm{N}\left(0, \sigma_{d}^{2}\right) ; s_{k: i j}$ is the random effect of sample $k$ within farm $i$ and day $j, \sim \mathrm{N}\left(0, \sigma_{s}^{2}\right)$; and $e_{i j k l}$ is the residual error and represents the analytical variance, $\sim \mathrm{N}\left(0, \sigma_{a}^{2}\right)$.

Because of the independence of the terms in [1], the variance of an observation is simply

$$
\operatorname{Var}\left(Y_{i j k l}^{n: z}\right)=\sigma_{f}^{2}+\sigma_{d}^{2}+\sigma_{s}^{2}+\sigma_{a}^{2}
$$

Two important consequences on the interpretation of the results are derived from [2]. First, variances are additives, but the SD are not additives. That is, 


$$
\operatorname{SD}\left(Y_{i j k l}^{n: z}\right) \neq \sigma_{f}+\sigma_{d}+\sigma_{s}+\sigma_{a} .
$$

The additivity of the variances and the nonadditivity of the SD will be important to remember when interpreting the results. Second, the variance of nutrient $n$ in feed $z$ on a given farm $i$ is the sum of the last 3 terms in [2]. But animals would only experience the effect of $\sigma_{d}^{2}$ because $\sigma_{s}^{2}$ and $\sigma_{a}^{2}$ (i.e., the sampling and analytical variances) are components of variances due to the observer and do not represent a true change in feed composition.

The model for the monthly data included the random effects of farm and the residual error as follows:

$$
Y_{i j}^{n: z}=\mu+f_{i}+e_{i j}
$$

where $Y_{i j}^{n: z}$ is the observed value for nutrient $n$ within feed $z ; f_{i}$ is the random effect of farm $i, \sim \mathrm{N}\left(0, \sigma_{f}^{2}\right)$; and $e_{i j}$ is the residual error, $\sim \mathrm{N}\left(0, \sigma_{e}^{2}\right)$.

Because the monthly data did not involve duplicate samples and duplicate laboratory assays, the residual variance is really the sum of 3 confounded variances, i.e.,

$$
\sigma_{e}^{2}=\sigma_{m}^{2}+\sigma_{s}^{2}+\sigma_{a}^{2}
$$

where $\sigma_{m}^{2}$ is the true within-farm variation across months for nutrient $n$ of feed $z$. Assuming that $\sigma_{s}^{2}$ and $\sigma_{a}^{2}$ in the monthly data are the same as those found in the daily data, then the component of variance due to month is easily calculated as

$$
\sigma_{m}^{2}=\sigma_{e}^{2}-\sigma_{s}^{2}-\sigma_{a}^{2} .
$$

All variance components were assumed independent and were estimated using restricted maximum likelihood (REML) methods. For the monthly sampling project, statistics were only calculated for feed ingredients that had at least 3 samples over the 12 -mo period on at least 5 farms. The ingredients that were statistically analyzed are in Table 1. Except for TMR samples and a few silages on 2 farms, no duplicates samples were taken in the monthly sampling project. Therefore, variation could only be partitioned into farm to farm and month to month. As explained algebraically in [5], the month-to-month variance includes sampling, analytical, and true month-to-month variance. To partition the variance in TMR composition, the same approach was used, but the model included the random effects of farm, duplicate sample nested within farm and month, and a residual term. To compare day-to-day variance
Table 1. Number of farms and number of samples per farm (maximum was one sample per month) for different ingredients fed on 47 different farms

\begin{tabular}{lccc}
\hline Feed & $\begin{array}{c}\text { Number } \\
\text { of farms }\end{array}$ & $\begin{array}{c}\text { Samples } \\
\text { per farm }\end{array}$ & $\begin{array}{c}\text { Total } \\
\text { samples }\end{array}$ \\
\hline Almond hulls & 6 & 5 to 8 & 39 \\
Canola meal & 12 & 3 to 7 & 67 \\
Soybean meal & 23 & 3 to 12 & 150 \\
Corn grain & 32 & 3 to 13 & 178 \\
High-moisture corn & 26 & 4 to 14 & 247 \\
Dried distillers grains & 17 & 3 to 12 & 119 \\
Wet distillers grains & 7 & 3 to 11 & 47 \\
Corn gluten feed & 11 & 3 to 12 & 60 \\
Wet corn gluten feed & 5 & 3 to 11 & 41 \\
Wet brewers grains & 12 & 4 to 12 & 125 \\
Whole cottonseed & 20 & 3 to 9 & 130 \\
Corn silage & $53^{2}$ & 3 to 19 & 627 \\
Mixed hay & 7 & 3 to 13 & 41 \\
Alfalfa hay & 28 & 3 to 14 & 263 \\
Mixed silage & 14 & 3 to 17 & 101 \\
Alfalfa silage & $49^{2}$ & 3 to 18 & 453 \\
Small grain silage & 11 & 3 to 14 & 94 \\
Straw & 16 & 3 to 12 & 127 \\
\hline
\end{tabular}

${ }^{1}$ To be included, a farm had to provide at least 3 samples of a given feed. Feeds were only included in the summary if they were fed on at least 5 farms.

${ }^{2}$ These numbers represent independent silos within a farm that were being fed from at the same time (e.g., one silo was identified as conventional silage and another silo was identified as brown-midrib silage).

with month-to-month variance in corn silage and haycrop silage, analytical and sampling variances for the monthly samples were assumed to be similar to the estimates obtained from the daily sampling project. The analytical and sampling variances estimated using the daily data were subtracted from the residual variance obtained with the monthly samples (i.e., we made use of Equation [6]). The square root of the remainder was calculated and is the estimate of true month-tomonth SD. Simple statistics for both daily and monthly samples were calculated using the univariate procedure of SAS.

\section{RESULTS AND DISCUSSION}

\section{Daily Sampling of Silages}

The mean concentrations of nutrients for corn-silage samples in the daily sampling project (Table 2) were generally similar to average concentrations observed in broader databases (e.g., DairyOne, 2015). However, depending on the nutrient, the SD in the broader database was 1.7 to 2.4 times greater in the broad database than for our sample. Our sample contained silage grown in a single year on 11 farms within 2 relatively narrow geographic areas as opposed to multiple years and widespread geographic distribution for the broad database. Because the haycrop silage classification 
Table 2. Descriptive statistics for corn silage and haycrop silage sampled over 14 consecutive days on 11 Ohio and Vermont farms (\% of DM)

\begin{tabular}{|c|c|c|c|c|}
\hline Item & Mean & $\mathrm{SD}$ & Range & $\begin{array}{l}\text { 10th-90th } \\
\text { Percentile }\end{array}$ \\
\hline \multicolumn{5}{|c|}{ Corn silage $(\mathrm{n}=504)$} \\
\hline $\mathrm{DM}$ & 37.0 & 5.23 & $26.2-49.0$ & $30.3-44.0$ \\
\hline NDF & 39.1 & 4.03 & $30.8-50.9$ & $34.3-45.0$ \\
\hline Starch & 32.8 & 4.33 & $14.3-44.0$ & $27.1-38.6$ \\
\hline Ash & 3.57 & 0.50 & $2.4-8.3$ & $3.1-4.2$ \\
\hline \multicolumn{5}{|c|}{ Haycrop silage $(\mathrm{n}=504)$} \\
\hline $\mathrm{DM}$ & 41.7 & 8.00 & $28.3-70.5$ & $31.9-52.1$ \\
\hline $\mathrm{NDF}$ & 49.9 & 6.61 & $32.7-65.2$ & $43.0-59.5$ \\
\hline $\mathrm{CP}$ & 16.3 & 2.72 & $10.8-23.2$ & $12.7-19.5$ \\
\hline Ash & 9.30 & 1.86 & $6.3-15.3$ & $6.9-11.6$ \\
\hline
\end{tabular}

in our study contained different types of forage (e.g., grasses and legumes), the overall variances have limited interpretable meaning.

For both forages and for most nutrients, the farm-tofarm SD was large (Table 3). Although farm-to-farm variation was the major source of variation for both silages and all nutrients (70 to $90 \%$ of total variation; data not shown), the goal of this project was to determine within-farm variation and partition it into important variance components (Table 3 ). The large proportion of variance attributable to farm indicates that the nutrient composition of silages are farm specific. Data from feed-composition tables or other farms probably will not accurately represent a silage on a specific farm. However, farm-to-farm variation in silage composition will not be discussed further.

For all nutrients and both silages, analytical variation was the smallest contributor to within-farm variation (generally $<15 \%$ of within-farm variance). For the nutrients that were assayed in both corn silage and haycrop silage, the SD for assay were substantially greater for corn silage than for haycrop silage. Subsampling at the laboratory could explain much of these differences between silages because of the large differences in nutrient composition among silage particles (e.g., grain, cob, stalks, leaves) of corn silage (Hunt et al., 1989).

Sampling was the greatest source of within-farm variation for nutrients other than DM (sampling and true day-to-day variation were about equal for haycrop NDF concentrations). For DM concentration, true day to day was the major source of variation. Within a 14-d period, greater real changes in silage DM than for other nutrients could be expected. Silage DM could be influenced by rain or snow events during the sampling period, and for haycrop silage, harvest DM concentrations could change substantially even when the crop was mowed and chopped the same day. For corn silage over a 14-d sampling period, true day-to-day variation accounted for less than 50\% and usually less than $34 \%$ of within-farm variation in important nutrients. The substantial amount of observer variation (sampling + analytical) relative to the amount of true day-to-day variation indicates that a change in nutrient composition between 2 single samples of silage taken over a

Table 3. Farm, sampling, analytical, and true day-to-day variation in nutrient composition (\% of DM) of corn silage and haycrop silage sampled over 14 consecutive days on 11 Ohio and Vermont farms ${ }^{1}$

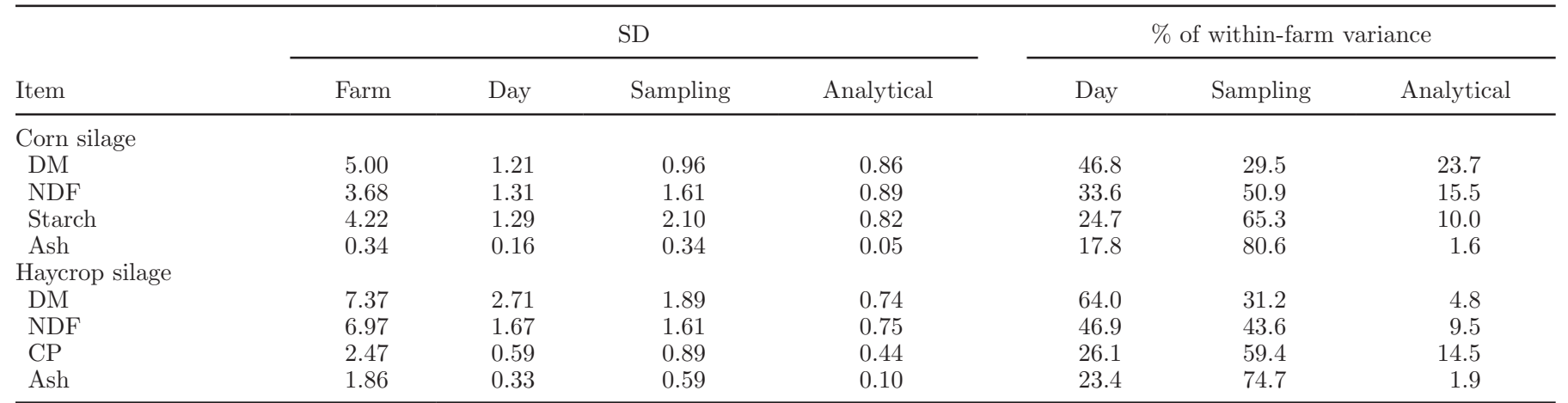

${ }^{1}$ Both corn and haycrop silages were sampled daily in duplicate on 7 farms, and single daily samples were taken on 4 farms. Total variance was partitioned into farm (farm to farm), sampling (variation between duplicate samples taken on the same day on the same farm), analytical (variation between duplicate assays of the same sample), and day (true day-to-day variation). Within-farm variance was partitioned into day, sampling, and analytical variances. The reported SD are the square roots of each variance component. 


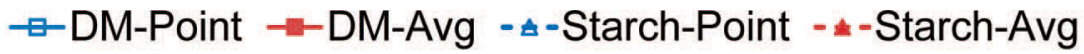

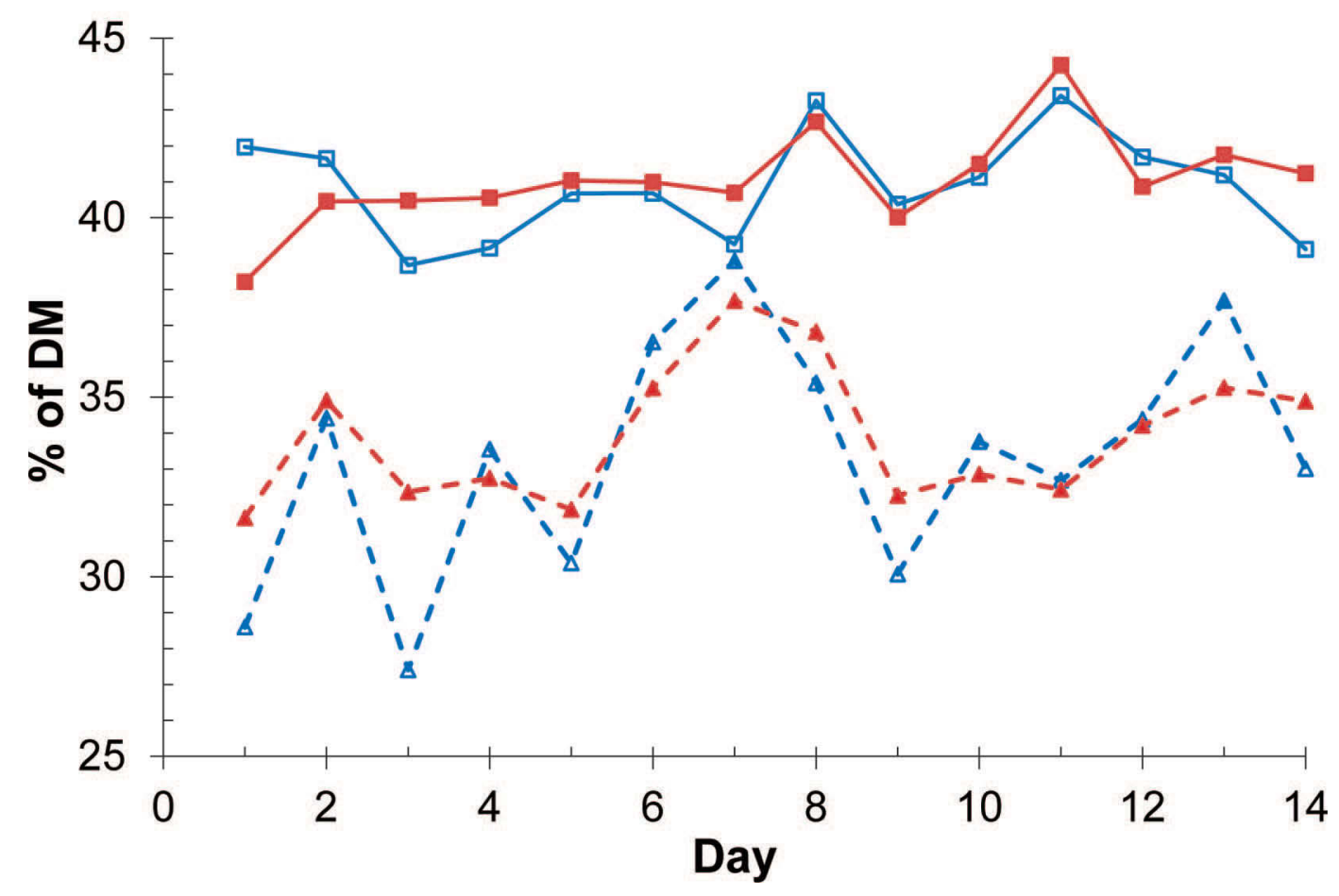

Figure 1. Effect of duplicate sampling and assays on variation in DM (solid lines) and starch (dashed lines) concentrations in corn silage from one commercial dairy farm. Each point on the lines with the closed symbols (red) is a mean of duplicate samples assayed in duplicate. Avg $=$ average. Each point on the lines with open symbols (blue) was randomly chosen from the 4 data points that made up the mean for that specific day. This figure is for illustrative purposes; the effect of duplicate sampling and assays may differ for other farms. Color version available online.

short period of time may not be real and modifying the diet based on an apparent change in nutrient composition may not be warranted. The concentrations of DM and starch in corn silage from an example farm over $14 \mathrm{~d}$ is in Figure 1. On each day, 4 analytical results were obtained (duplicate samples each assayed in duplicate). One line for each nutrient contains the daily mean of those 4 values, and the other line for each nutrient contains only one data point for each day (randomly selected from the 4 daily observations). For DM, the SD over days was slightly less for the means than for the point estimates (1.35 vs. 1.48) and the mean line over time appears smoother. However, on this example farm the single point estimates followed the mean line closely indicating a single point rather than means of duplicate samples and duplicate assays would be adequate for DM (day to day was the major source of variation for corn-silage DM). A different interpretation is obtained for starch in this instance. The SD over days for the mean line was substantially less than for the point estimate line (1.9 vs. 3.3), and the mean line appears much smoother. On several days, the point estimate was substantially different from the 4 observation means. In this example, using the mean of duplicate samples for starch increased the confidence that the analytical data represented the silage.

\section{Monthly Sampling Project}

By assuming that sampling and analytical variances are independent of farm and sampling interval (daily vs. monthly), we could compare within-farm monthly variation over 1 yr (Table 4) with daily variation over a 2 -wk period (Table 3). As would be expected estimated monthly variation was substantially greater than daily variation. Daily variation usually comprised 20 to $60 \%$ of the within-farm variance for corn and haycrop silages, but monthly variation comprised approximately 50 to $90 \%$ of the within-farm variance. Although sampling variation generally made up a smaller proportion of within-farm variation when silages were sampled over a 12 -mo period than when sampled over a 2 -wk period, sampling variation was still substantial. This suggests duplicate sampling and averaging is beneficial for different sampling schedules.

Sampling TMR. Sampling and analyzing TMR can be used to compare the composition of the delivered diet to the formulated diet nutrient specification. Dif- 
Table 4. Variation (SD units) and estimated variance partitioning for different nutrients in corn silage and alfalfa silage sampled over 12 consecutive months from 53 (corn silage) and 49 (alfalfa silage) independent silos on 47 farms

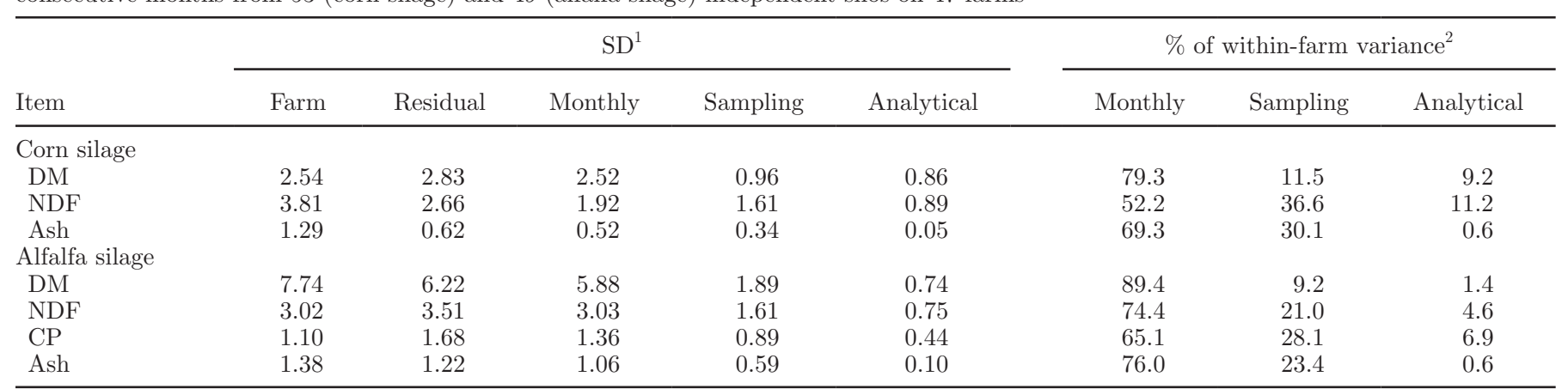

${ }^{1}$ Residual SD includes sampling, analytical, and true month-to-month variation.

${ }^{2}$ True monthly variance was estimated by removing sampling and analytical variances (using variance estimates from the daily sampling project; Table 3) from the residual variance.

ferences from target specifications could be caused by changes in the composition of the ingredients or by deviations from the recipe or ration delivery protocols by the feeder. However, if sampling and analytical variation is large, results from a single TMR sample can be misleading. For most of the commonly assayed nutrients, sampling plus analytical variation was the major source of variation in TMR composition (Table $5)$ in this survey.

As an example, let us examine the quality of the information from a single TMR sample when NDF is used as an indicator to compare the delivered diet to the formulated diet. For simplicity, we shall assume that the diet was formulated for $30 \% \mathrm{NDF}$ and that NDF concentration is normally distributed (this is a reasonable assumption in this context, considering that the diet is a mixture of many ingredients). The $95 \%$ confidence limits (CL) on the expected value of the laboratory assay are found as

$$
\begin{gathered}
\text { lower } \mathrm{CL}=30-\left(z_{0.05} \times 1.81\right)= \\
30-(1.96 \times 1.81)=26.5 \% \text { and } \\
\text { upper } \mathrm{CL}=30+\left(z_{0.05} \times 1.81\right)= \\
30+(1.96 \times 1.81)=33.5 \% .
\end{gathered}
$$

where $\mathrm{z}_{0.05}$ is the abscissa at a $5 \%$ probability for the cumulative normal distribution (i.e., 1.96), and 1.81 in the above equations is the sampling + analytical SD obtained in this project (Table 5). Thus, the laboratory results would have to be either less than $26.45 \% \mathrm{NDF}$ or more than $33.45 \%$ to conclude with a $95 \%$ probability that the delivered diet was out of specifications.

Table 5. Farm, sampling plus analytical, and true month-to-month variation in nutrient composition (DM basis) of TMR (from a single pen per farm) from 47 farms sampled over 12 consecutive months ${ }^{1}$

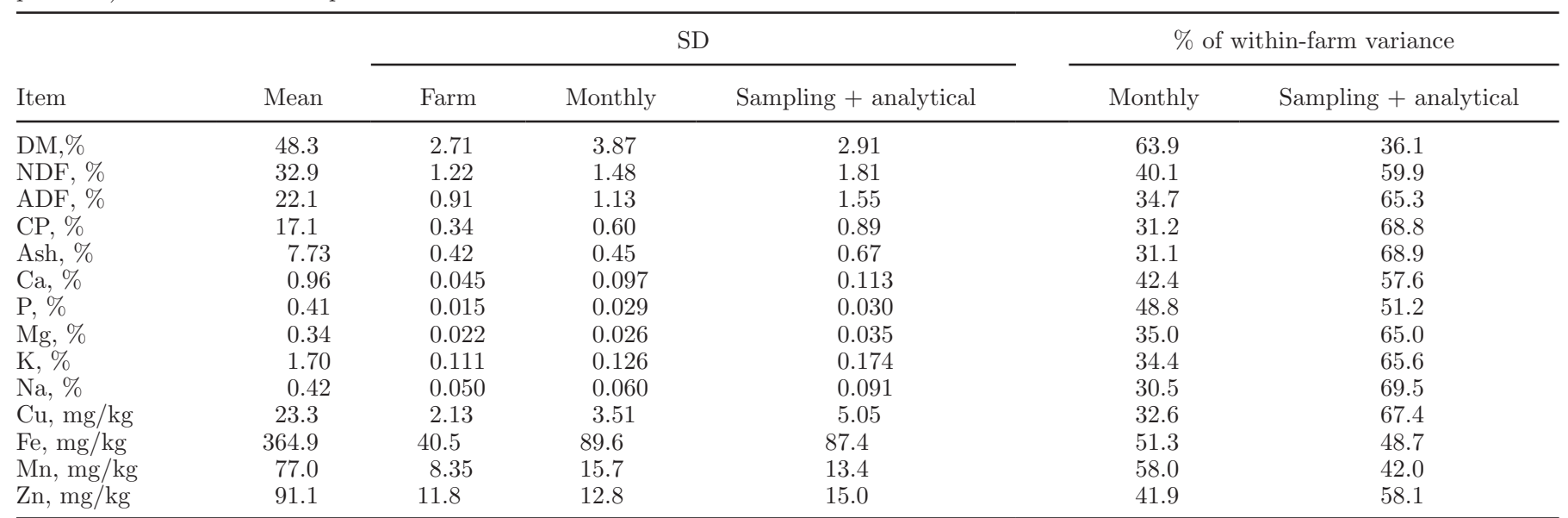

${ }^{1}$ Variance was partitioned into farm-to-farm variance (farm), month-to-month variance (monthly), and variation between duplicate samples and analytical variation (sampling + analytical). Because assays were not replicated on samples, sampling and analytical variances could not be separated. 
If more than one independent sample is taken, then the SD of the mean must account for the number of samples (i.e., $\mathrm{SEM}=1.81 \div \sqrt{ } n$ ). For example, if 2 samples were taken, the $95 \%$ CL on the expected value of the mean of the 2 samples would be

$$
\begin{gathered}
\text { lower } \mathrm{CL}=30-[1.96 \times(1.81 \div \sqrt{ } 2)]=27.9 \% \text { and } \\
\text { upper } \mathrm{CL}=30+[1.96 \times(1.81 \div \sqrt{ } 2)]=32.1 \%
\end{gathered}
$$

Under field conditions, one may not want to reach the traditional $95 \%$ confidence used in science. Using a table for the cumulative function of the standard normal distribution, one can easily find the $\mathrm{z}$ value associated with a desired probability. The optimal CL to use in a given situation is dependent on the costs of the type I error (i.e., one concludes that the delivered diet did not meet specifications when in fact it did) and type II error (one concludes that the delivered diet did meet specifications when in fact it did not). To our knowledge, this has not been studied, but an approach similar to what St-Pierre and Cobanov (2007a,b) used in the context of feed monitoring could be investigated. Theoretically, the power of detection would be increased if many nutrients were considered jointly (i.e., using a multivariate approach).

Within-Farm Variation for Common Feeds. Several common feeds were sampled on multiple farms at multiple times (Table 1) allowing us to determine among-farm and within-farm variation (Tables 6, 7, and 8 and supplemental material; http://dx.doi. org/10.3168/jds.2015-9431). Duplicate sampling and duplicate assays were not conducted; therefore, within-farm variation includes true month-to-month variation, sampling variation, and analytical variation.
For some feeds such as distillers grains (Spiehs et al., 2002; Belyea et al., 2010; Buckner et al., 2011) and wheat middlings (Cromwell et al., 2000), some sources of variation have been quantified. However, previously published data on within-farm variation for most feeds are not available. The magnitude of the overall, farm-to-farm, and within-farm variation can be used to determine whether composition data from a feed library is adequate (i.e., small overall SD), whether feeds should be sampled on individual farms (i.e., high farm $\mathrm{SD}$ ), or whether multiple samples are needed (i.e., high within-farm SD). Evaluating among-farm variation and within-farm variation is useful in determining optimal sampling schedules. Composition data from tables or libraries are probably adequate for feeds with low total variation. Feeds with low among-farm variation but high within-farm variation should be sampled in duplicate over time within a farm to determine the major sources of within-farm variation (e.g., sampling vs. true time variation). High within-farm variation suggests that using laboratory results from a single sample has a high risk of being incorrect.

Data in Tables 6,7 , and 8 are used to illustrate different scenarios (data for other feeds are available in the supplemental materials; http://dx.doi.org/10.3168/ jds.2015-9431). Cottonseed (Table 6) had high residual SD for most nutrients but small farm SD. Subsampling error following grinding can be high for cottonseed (Calhoun et al., 2004), which is likely a major source of residual variation. The high residual variation indicates that data from a single sample may be poorly representative of the feed and could lead to formulation errors. The relatively low farm variation suggests that for many nutrients, a library or table value should be used for whole cottonseed.

Table 6. Mean composition and measures of total, farm-to-farm, and within-farm variation (i.e., residual) for

\begin{tabular}{|c|c|c|c|c|c|}
\hline \multirow{2}{*}{$\begin{array}{l}\text { Whole cottonseed } \\
(\mathrm{n}=130)\end{array}$} & \multirow[b]{2}{*}{ Mean } & \multirow{2}{*}{$\begin{array}{l}\text { 10th-90th } \\
\text { Percentile }\end{array}$} & \multicolumn{3}{|c|}{$\mathrm{SD}$} \\
\hline & & & Total & Farm & Residual \\
\hline DM, $\%$ & 89.9 & $87.2-92.7$ & 2.11 & 1.47 & 1.54 \\
\hline $\mathrm{CP}, \%$ & 21.8 & $19.7-23.6$ & 1.68 & 0.41 & 1.63 \\
\hline NDF, $\%$ & 45.6 & $41.0-50.7$ & 4.14 & 0 & 4.14 \\
\hline Ash, $\%$ & 4.4 & $3.9-4.9$ & 0.55 & 0.069 & 0.54 \\
\hline $\mathrm{Ca}, \%$ & 0.22 & $0.16-0.30$ & 0.091 & 0 & 0.091 \\
\hline P, \% & 0.58 & $0.48-0.68$ & 0.085 & 0.048 & 0.070 \\
\hline $\mathrm{Mg}, \%$ & 0.39 & $0.35-0.44$ & 0.046 & 0.021 & 0.041 \\
\hline $\mathrm{K}, \%$ & 1.30 & $1.17-1.44$ & 0.092 & 0.055 & 0.075 \\
\hline $\mathrm{Na}, \%$ & 0.05 & $0.01-0.09$ & 0.088 & 0 & 0.088 \\
\hline $\mathrm{Cu}, \mathrm{mg} / \mathrm{kg}$ & 8.8 & $6-11$ & 3.69 & 0.407 & 3.66 \\
\hline $\mathrm{Fe}, \mathrm{mg} / \mathrm{kg}$ & 82.6 & $50-120$ & 38.2 & 13.8 & 35.7 \\
\hline $\mathrm{Mn}, \mathrm{mg} / \mathrm{kg}$ & 19.5 & $13-26$ & 9.80 & 1.89 & 9.63 \\
\hline $\mathrm{Zn}, \mathrm{mg} / \mathrm{kg}$ & 41.9 & $33-52$ & 10.8 & 3.25 & 10.3 \\
\hline
\end{tabular}
whole cottonseed ${ }^{1}$

${ }^{1}$ Samples came from 20 different farms that sampled whole cottonseed for at least 3 different months during the year. 
Table 7. Mean composition and estimates of total, farm-to-farm, and within-farm variation (i.e., residual) for dry and high-moisture corn grain ${ }^{1}$

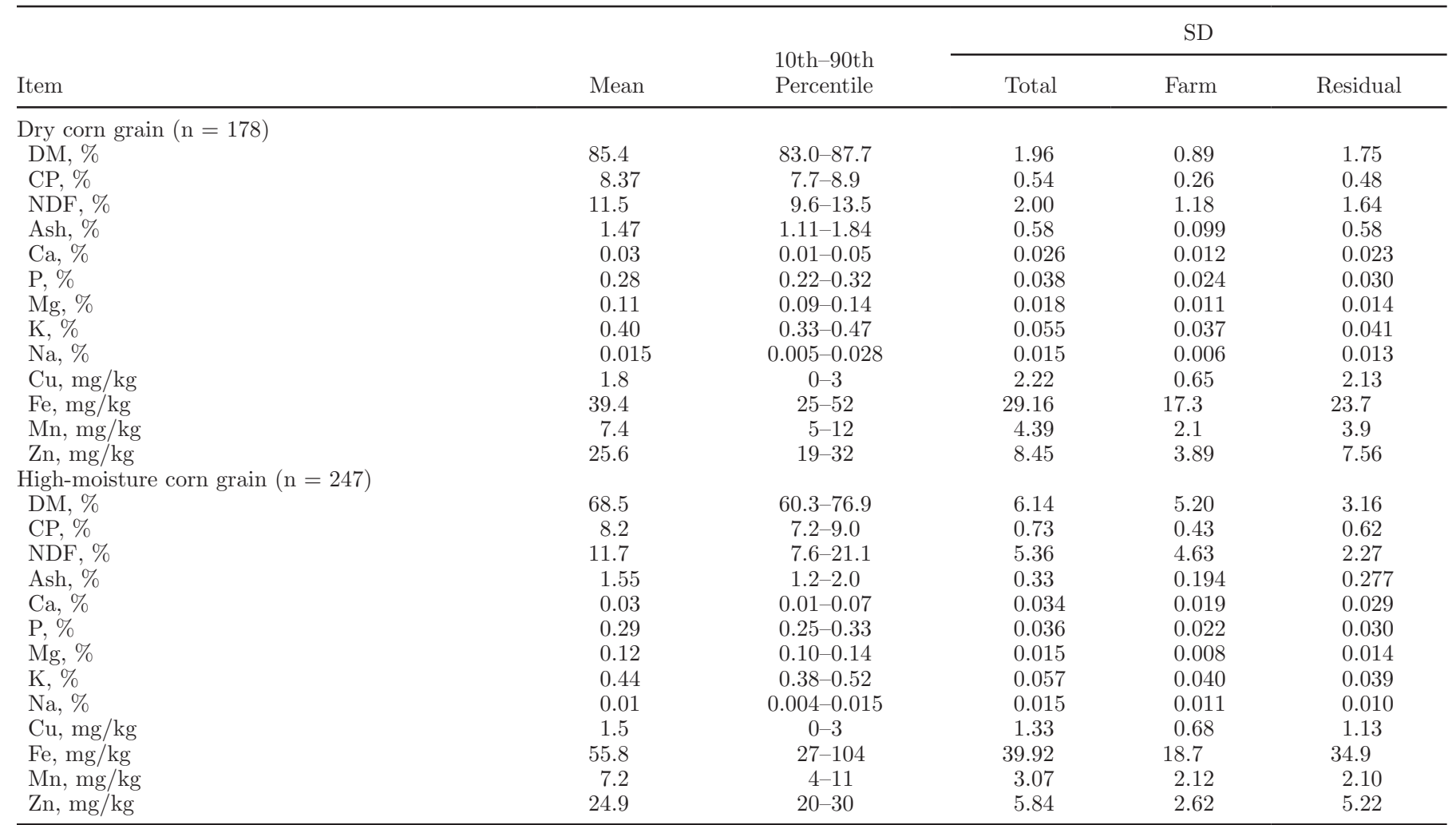

${ }^{1}$ Dry corn samples came from 32 farms and high-moisture corn samples came from 26 farms (a farm had to sample the feed at least 3 different months during the year).

High-moisture corn is usually grown and fed locally, whereas dry corn is a national commodity, and supplies are often blended from multiple sources. For dry corn grain (Table 7), the within-farm SD was generally greater than farm-to-farm SD, and the overall SD were generally small. The small farm-to-farm SD indicates that library values or mean nutrient composition from multiple farms is probably adequate. Furthermore, because sampling and analytical variation can be major sources of within-farm variation, taking a single sample from a single farm may result in values that do not represent the population. A different conclusion is reached with high-moisture corn. Farm-to-farm SD was usually greater than within-farm SD. This is expected because in most situations high-moisture corn is grown on the specific farm and is harvested based on specific conditions for a farm. The high farm SD for high-moisture corn indicates that farm-specific composition data should be used. The relatively high within-farm SD indicates that multiple samples should be taken within each farm.

Data in Table 8 contrast results from a well-defined commodity (soybean meal) with 2 different by-products (dried distillers grains and wet brewers grains).
Total variance for most nutrients was greater for the 2 by-products than for soybean meal. However, when variation is partitioned, differences between the feeds become even more pronounced. Farm-to-farm SD for distillers grains and brewers grains for some important nutrients was 3 to 10 times greater than farm-to-farm SD for soybean meal. Residual variance between the 2 dry feeds was generally similar and less than the wet feed. Obtaining a representative sample of a wet feed would be more difficult than sampling dry feeds. The small farm-to-farm SD for soybean meal indicates that values across farms can be averaged or table values could be used for ration formulation. For dried distillers and wet brewers grains, individual farm data should be used.

Variability in nutrient composition of distillers grains is a concern and may contribute to a discounted price or limited inclusion rates (Shurson and Alghamdi, 2008). Several studies have evaluated the nutrient composition of distillers grains and identified major sources of variability (Spiehs et al., 2002; Belyea et al., 2010; Buckner et al., 2011). The nutrient composition of distillers grains is more variable than the nutrient composition of standard feeds such as corn and soybean meal (Tables 
Table 8. Mean composition and estimates of total, farm-to-farm, and within-farm variation (i.e., residual) for dried distillers grains, soybean meal, and wet brewers grains ${ }^{1}$

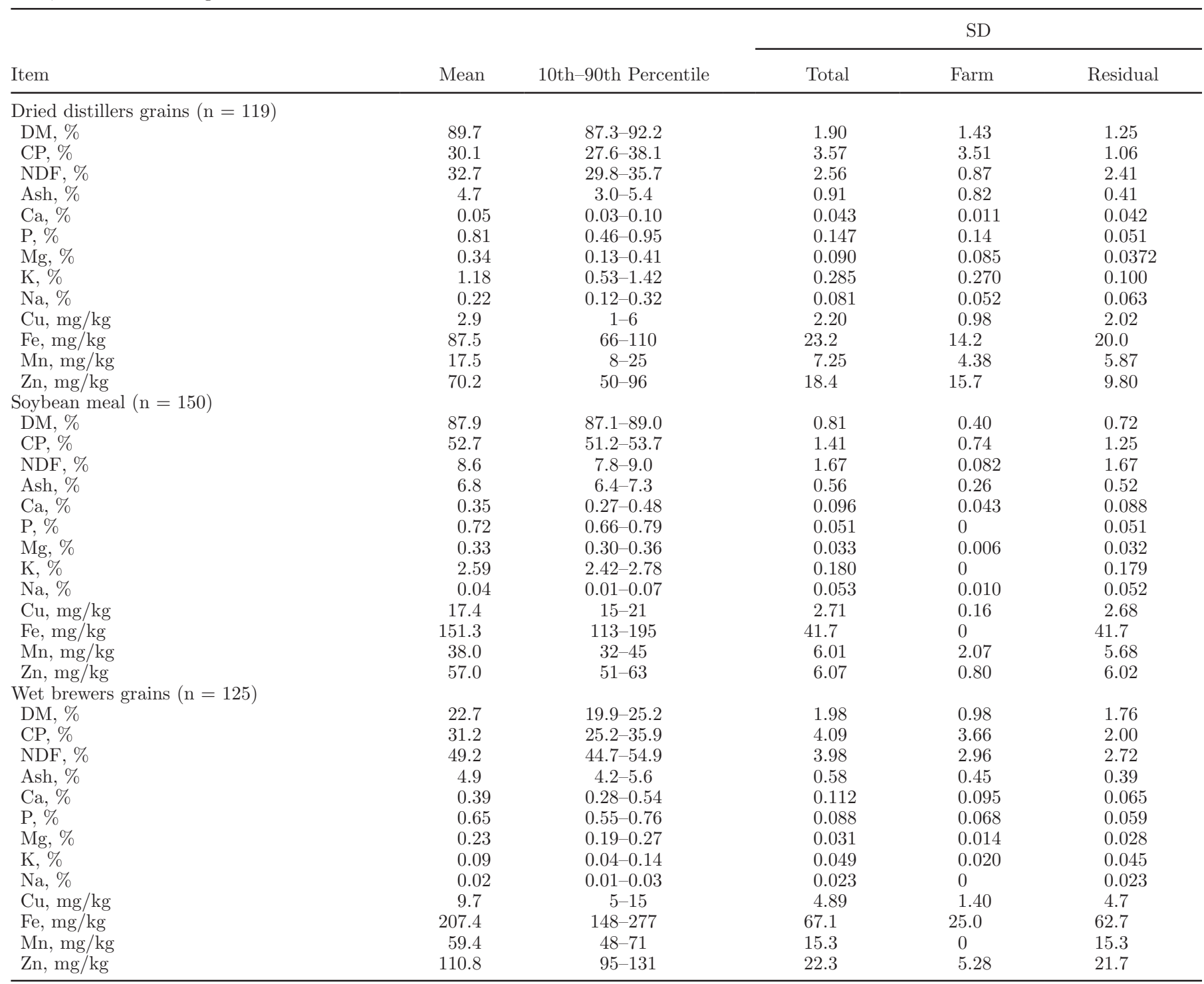

${ }^{1}$ Samples came from 17, 23, and 12 farms for distillers grains, soybean meal, and wet brewers grains farms (a farm had to sample the feed at least 3 different months during the year).

7 and 8). However variability in distillers grains was similar to that found in wet brewers grains (and other by-products, see supplemental material; http://dx.doi. org/10.3168/jds.2015-9431). For major nutrients, both farm-to-farm and residual SD are high for both byproducts, indicating farm-specific data are needed and multiple samples within a farm should be taken and averaged.

Table 9 should assist nutritionists and producers in deciding which feeds to sample at the farm and how to summarize results. Feeds that significantly vary between farms should be frequently sampled and results summarized by farm. The decision model proposed by
St-Pierre and Cobanov (2007a) could be used to determine sampling frequency, number of samples to be taken, and intervention threshold (i.e., to rebalance the diet or not). Feed tables should be used for those feeds where farm was not a significant source of variation. Likewise, feed tables should be used for dried distillers grains with solubles if the feed is purchased as a pure commodity without a specific identity in regard to the production plant of origin. Otherwise, specific composition data summarized by plant of origin may be warranted.

Nutritionists using stochastic programming to take into account feed variation during diet formulation 
Table 9. Recommendations regarding level of sampling and data summarization for feeds evaluated in this project

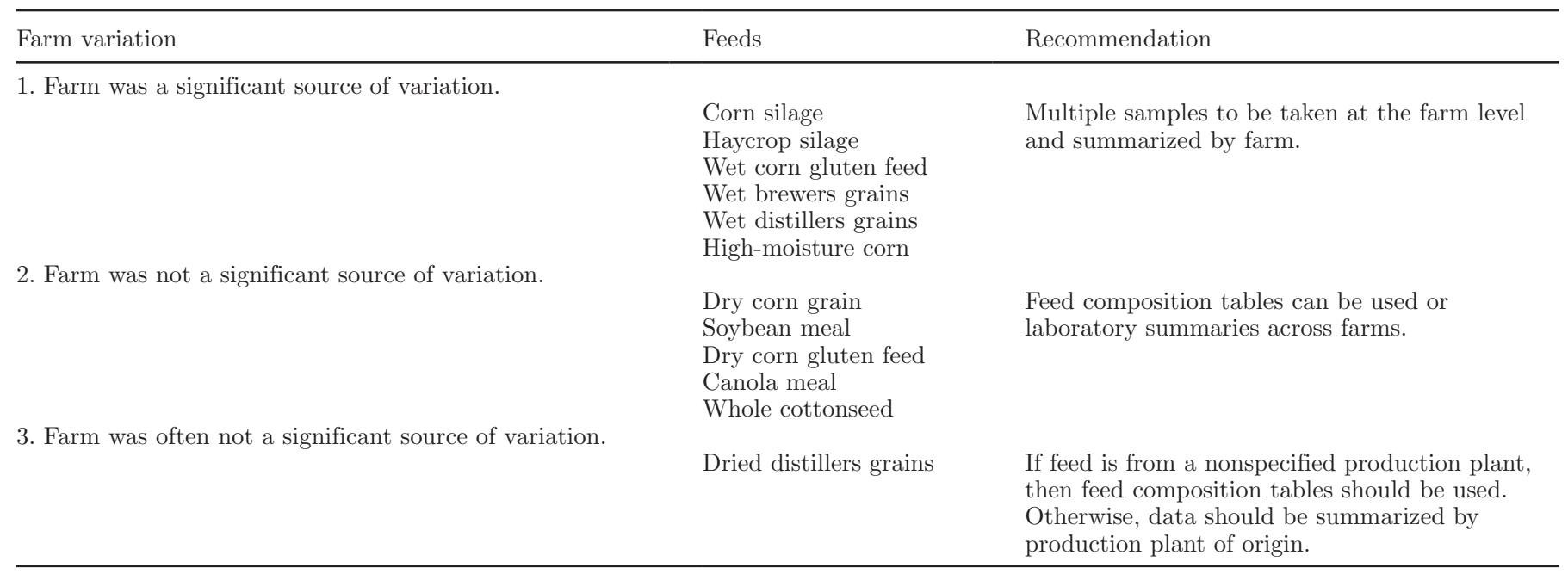

should use estimates of variances that are free of sampling and analytical variances (i.e., use true feed composition variances as opposed to apparent ones). Data in Supplemental Tables S1 and S2 (http://dx.doi. org/10.3168/jds.2015-9431) should be useful in that regard.

\section{CONCLUSIONS}

Substantial variation in nutrient composition for many feeds exists. However, that variation in not necessarily partitioned the same for different feeds. Farmto-farm variation was extremely large for silages but was small for feeds such as dry corn and soybean meal. Within-farm variation was also large for many feeds. Over short periods (weeks), sampling was the major source of day-to-day variation within farm for silages. Over longer periods (monthly samples over one year), true time variation was the major source of withinfarm variation; however, sampling variation was still significant. Overall, data from this project indicate the need to take multiple samples within farms and use averages for ration formulation, rather than using data from single samples. For some feeds such as soybean meal and dry corn, table values may actually be more accurate than a single farm sample.

\section{ACKNOWLEDGMENTS}

The authors thank Donna Wyatt for conducting many of the assays and organizing the multitude of data. We thank Chris Hill (formerly with Poulin Grain Inc., Newport, VT) for taking the samples from the 3 Vermont dairy farms. This project could not have been completed without the help of the cooperating farms and the collaborating nutritionists who took samples and provided data. The nutritionists were Todd Ardrey, Jim Barmore, Larry Bock, Shannon Cobb, David Danforth, Mike DeGroot, Mich Etchebarne, Marc Fiegl, Tim Hanzie, Dave Hawk, King Hickman, Corwin Holtz, Allen Johnson, Matt Kauffman, Bud Keister, Nate Kiefer, Kevin Klinect, Kevin Lager, Michele Lahmers, Ben Mercer, Dwight Roseler, Lyle Ruprecht, Dan Sevcik, Brian Troyer, John Winchell, Steve Woodford, and Clay Zimmerman. This project was supported by National Research Initiative Competitive Grant no. 2009-55206-05242 from the USDA National Institute of Food and Agriculture (Washington, DC).

\section{REFERENCES}

AOAC International. 2000. Official Methods of Analysis. Vol. 1 and 2. 17th ed. AOAC Int., Gaithersburg, MD.

Belyea, R. L., K. D. Rausch, T. E. Clevenger, V. Singh, D. B. Johnston, and M. E. Tumbleson. 2010. Sources of variation in composition of DDGS. Anim. Feed Sci. Technol. 159:122-130.

Black, J. R., and J. Hlubik. 1980. Basics of computerized linear programs for ration formulation. J. Dairy Sci. 63:1366-1378.

Buckner, C. D., M. F. Wilken, J. R. Benton, S. J. Vanness, V. R. Bremer, T. J. Klopfenstein, P. J. Kononoff, and G. E. Erickson. 2011. Nutrient variability for distillers grains plus solubles and dry matter determination of ethanol by-products. Prof. Anim. Sci. 27:57-64.

Calhoun, M. C., P. J. Wan, S. W. Kuhlmann, and B. C. Baldwin Jr. 2004. Variation in the nutrient and gossypol content of whole and processed cottonseed. Pages 21-38 in Proc. Mid-south Rum. Nutr. Conf., Arlington, TX. Texas Animal Nutrition Council, Dallas, TX.

Cromwell, G. L., T. R. Cline, J. D. Crenshaw, T. D. Crenshaw, R. A. Easter, R. C. Ewan, C. R. Hamilton, G. M. Hill, A. J. Lewis, D. C. Mahan, J. L. Nelssen, J. E. Pettigrew, T. L. Veum, and J. T. Yen. 2000. Variability among sources and laboratories in analyses of wheat middlings. J. Anim. Sci. 78:2652-2658.

DairyOne. 2015. Feed composition libraries. Accessed Jan. 30, 2015 http://dairyone.com/analytical-services/feed-and-forage/feedcomposition-library/interactive-feed-composition-library/. 
Hunt, C. W., W. Kezar, and R. Vinande. 1989. Yield, chemical composition and ruminal fermentability of corn whole plant, ear, and stover as affected by maturity. J. Prod. Agric. 2:357-361.

Kertz, A. F. 1998. Variability in delivery of nutrients to lactating dairy cows. J. Dairy Sci. 81:3075-3084.

NANP (National Animal Nutrition Program). 2015. Feed and ingredient information. Accessed Jan. 30, 2015. http://nanp-nrsp-9.org/ feed $/$ search $/$ ?animal $=$ all\&feed $=$.

NRC. 2001. Nutrient Requirements of Dairy Cattle. 7th rev. ed. ed. Natl. Acad. Press, Washington, DC.

SAS Institute Inc. 2011. SAS/Stat ${ }^{\circledR} 9.3$ User's Guide. SAS Inst. Inc., Cary, NC.

Shurson, J., and A. S. Alghamdi. 2008. Quality and new technologies to create corn co-products from ethanol production. Pages 231-259 in Using Distillers Grains in the US and International Livestock and Poultry Industries. B. A. Babcock, D. J. Hayes, and J. D. Lawrence, ed. Iowa State Univ., Ames.

Sniffen, C. J., R. W. Beverly, C. S. Mooney, M. B. Roe, A. L. Skidmore, and J. R. Black. 1993. Nutrient requirements versus supply in the dairy cow: strategies to account for variability. J. Dairy Sci. 76:3160-3178.

Sova, A. D., S. J. LeBlanc, B. W. McBride, and T. J. DeVries. 2014. Accuracy and precision of total mixed rations fed on commercial dairy farms. J. Dairy Sci. 97:562-571.
Spiehs, M. J., M. H. Whitney, and G. C. Shurson. 2002. Nutrient database for distillers dried grains with solubles produced from new ethanol plants in Minnesota and South Dakota. J. Anim. Sci. 80:2639-2645.

St-Pierre, N. R., and B. Cobanov. 2007a. A model to determine the optimal sampling schedule of diet components. J. Dairy Sci. 90:5383-5394.

St-Pierre, N. R., and B. Cobanov. 2007b. Optimal sampling schedule of diet components: Model robustness to departure from assumptions. J. Dairy Sci. 90:5395-5404.

St-Pierre, N. R., and W. R. Harvey. 1986. Uncertainty in composition of ingredients and optimal rate of success for a maximum profit total mixed ration. J. Dairy Sci. 69:3075-3089.

Van Soest, P. J., J. B. Robertson, and B. A. Lewis. 1991. Methods for dietary fiber, neutral detergent fiber, and nonstarch polysaccharides in relation to animal nutrition. J. Dairy Sci. 74:3583-3597.

Weiss, W. P., and D. J. Wyatt. 2000. Effect of oil content and kernel processing of corn silage on digestibility and milk production by dairy cows. J. Dairy Sci. 83:351-358. 